\title{
Volviendo a los orígenes del servicio social. El caso de la Escuela de asistentes sociales de Santa Fe*
}

\author{
Revisiting the origins of social service. \\ The case of the School of Social Workers \\ of Santa Fe
}

\author{
Mariela Rubinzal \\ Consejo Nacional de Investigaciones Científicas y Técnicas \\ Universidad Nacional del Litoral \\ (Argentina) \\ mariela.rubinzal@gmail.com
}

\begin{abstract}
Este artículo se sitúa en los orígenes de la Escuela de Servicio Social de Santa Fe (creada en 1943), con el objetivo de analizar este proyecto educativo en relación a la coyuntura política, al desarrollo del Estado provincial, a la modernización en clave regional y a la visión de los funcionarios e intelectuales que llevaron adelante dicha empresa. Asimismo analizamos el perfil de las protagonistas de esta historia, a saber, las primeras asistentes sociales quienes buscaban integrarse plenamente en el mercado de trabajo como profesionales.
\end{abstract}

Palabras Clave: Servicio Social - Estado provincial - Modernización - Profesionales

\footnotetext{
*. Este trabajo se desprende de la investigación realizada para mi libro Historia de la Escuela de Servicio Social de Santa $\mathrm{Fe}$ (1943-2013), UNL, Santa Fe, 2014. Agradezco muy especialmente a Maria Pozzio sus exhaustivos comentarios y sugerencias para re-pensar algunos puntos de este texto; $\mathrm{y}$ a los evaluadores anónimos cuyas sugerencias dieron forma a esta última versión.
} 


\begin{abstract}
This article discusses the origins of the School of Social Service of the Santa Fe province (created in 1943), with the aim of analyzing this educational project in relation to the Argentina's political situation, the development of the provincial government, the regional modernization and the agents and intellectuals vision who carried out this initiative. We also analyze protagonist's profile of this story: the first social workers, women who sought to fully integrate themselves into the labor market as professionals.
\end{abstract}

Key Words: Social services - Professionals - Provincial state - Modernization

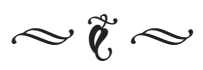

\section{Introducción: perspectiva y consideraciones metodológicas}

El surgimiento del servicio social en la Argentina ha sido explicado como una forma de control de la vida cotidiana; como el fruto de la acción de los médicos higienistas; como un proceso de transición de un saber tradicional a uno experto; como consecuencia del advenimiento del Estado de Bienestar e inclusive como resultado del modo de producción capitalista. ${ }^{1}$ En general

1. GRASSI, Estela, Las mujeres y la profesión de asistente social. El control de la vida cotidiana, Humanitas, Buenos Aires, 1989; TENTI FANFANI, Emilio, Estado y pobreza: estrategias típicas de intervención (2 volúmenes), CEAL, Buenos Aires, 1989; BRITOS, Gabriel, Asistencia Social en Rosario. Historia de su formación profesional, UNR, Rosario, 2003 (segunda Edición). PARRA, Gustavo, "Antimodernidad y Trabajo Social. Reflexiones en torno a la génesis de la profesión". Disponible en <http://www.ts.ucr.ac.cr/binarios/congresos/reg/ slets/slets-016-136.pdf> [Consulta: 18 de julio 2016] ALAYÓN, Norberto, Hacia la historia del trabajo social en la Argentina, Celats, Lima, 1980 y ALAYÓN, Norberto, "Acerca del trabajo social y la antimodernidad", en Social Work E Society, Essen, 2004, V. II, No 2, pp. 279-284; ROZAS PAGAZA, Margarita, Intervención profesional en relación a la cuestión social, Editorial Espacio, Buenos Aires, 2001. Es especialmente interesante el planteo de Donna Guy sobre la relación entre mujeres feministas todos estos enfoques coinciden en otorgar a la cuestión social -definida en un sentido amplio como las consecuencias de un rápido proceso de modernización- un papel central en dicho proceso. ${ }^{2}$ Partiendo de este consenso, y desde una perspectiva histórica, abordamos el estudio de la profesionalización del servicio social situándonos en los orígenes de la Escuela de Servicio Social de Santa Fe. ${ }^{3}$ No

profesionales y filántropas frente a la infancia. GUY, Donna, Las mujeres y la construcción del Estado de Bienestar. Caridad y creación de derechos en Argentina, Prometeo, Buenos Aires, 2011.

2. Britos señala que una correcta interpretación de esta temática se encuentra en la relación de la cuestión social con "el proceso transitivo del capitalismo competitivo al capitalismo monopolista”. BRITOS, Gabriel, Asistencia Social en Rosario. Historia de su formación profesional, UNR, Rosario, 2003, p. 28. Ver también ROZAS PAGAZA, Margarita, Intervención profesional..., Op. Cit.

3. La categoría de profesionalización la utilizamos en este trabajo para referirnos a un proceso histórico que incluye la existencia de profesionales que ejercen la actividad a tiempo completo; la formulación de reglas para el ejercicio de la profesión organizadas en un código deontológico; la creación de espacios de formación y escuelas; y la formación de una cultura profesional. Sobre el origen de las profesiones y los procesos de profesionalización, además de los clásicos, se puede consultar ABBOTT, Andrew, The System of Professions. 
obstante, entendemos que centrar el análisis exclusivamente en la existencia de la cuestión social, como lo hacen la mayoría de los trabajos disponibles, no ayuda a comprender el problema central que nos planteamos, a saber, por qué el Estado decide -en un momento dado- crear escuelas de asistentes sociales. En principio, una de las hipótesis que se propone en este artículo es que la creación de escuelas por parte del Estado fue una estrategia, entre otras, para abordar los problemas sociales y surge -esto es relevante- una vez que fracasan otras instancias de intervención.

La insuficiencia de la matriz explicativa que centra la atención predominantemente en la cuestión social está dada porque la emergencia de problemas sociales vinculados a la modernización es, en general, anterior

An Essay on the Division of Expert Labor, University of Chicago Press, Chicago, 1988; BOURDIEU, Pierre "La ilusión biográfica”, en BOURDIEU, Pierre, Razones Prácticas, Editorial Anagrama, Barcelona, 1997; DUBAR, Claude, La socialisation. Construction des identités sociales et professionnelles, Armand Colin, París, 1991; DUBAR, Claude y TRIPIER, Pierre, Sociologie des Professions, Armand Colin, París, 1998; FERNÁNDEZ PÉREZ, Jorge, "Elementos que consolidan al concepto profesión. Notas para su reflexión.", en Revista Electrónica de Investigación Educativa, México, 2001, V. III, No 1; FREIDSON, Eliot, Professional Powers. A Study of the Institutionalization of Formal Knowledge, University of Chicago Press, Chicago, 1986; GUILLEN, Mauro, "Profesionales y burocracia: Desprofesionalización, proletarización y poder profesional en las organizaciones complejas", en Revista española de investigaciones sociológicas, Madrid, 1990, N 51; LAZARSFELD, Paul, SEWELL, William y WILENSKY, Harold, La sociología de las profesiones, Paidós, Buenos Aires, 1967. Sobre la recepción de las teorías inglesas, americanas y francesas en la Argentina, ver PANAIA, Marta, Una revisión de la sociología de las profesiones desde la teoría crítica del trabajo en la Argentina. CEPAL - Colección Documentos de proyectos, 2007. al proceso de profesionalización del servicio social. Asimismo, la preocupación del Estado por resolver de manera eficiente los problemas planteados por la modernización -esto es, mediante la intervención de expertostampoco es una variable suficiente por sí sola. Muchos de los espacios de formación profesional fueron fruto de la iniciativa privada y no de la estatal. De tal forma argumentamos que la profesionalización del servicio social pudo desarrollarse a partir de que la cuestión social alcanzó una densidad considerable en la esfera pública y de que el Estado logró cierto grado de madurez y evolución institucional. En nuestro estudio pudimos ver que el Estado provincial estimuló la formación de asistentes sociales -creando una escuela- una vez que fracasaron otras alternativas de intervención y cuando contó con organismos y funcionarios preparados para dirigir políticas sociales. Teniendo en cuenta que la modernización es un proceso conflictivo y-sobre todo- desigual dentro de un mismo espacio nacional nuestro análisis profundiza en la coyuntura política y social santafesina. La acción del Estado provincial en esferas anteriormente libradas a la iniciativa privada y la aparición de nuevos profesionales en el mercado laboral generaron tensiones y conflictos entre diferentes actores. De esta manera, puede afirmarse que en los orígenes de la profesionalización de la asistencia social en Santa Fe cristalizó una matriz conflictiva. ${ }^{4}$

4. GONZÁLEZ LEANDRI, Ricardo, GONZÁLEZ BERNALDO, Pilar y SURIANO, Juan, La temprana cuestión social. La ciudad de Buenos Aires durante la segunda mitad del siglo XIX, Consejo Superior de Investigaciones Científicas (CISC), Madrid, 2010; BECERRA SOLÁ, Malena y BECERRA Natalia, "Intervención social en la Argentina de los años 30: la profesionalización de la asistencia social", en Historia Caribe, Barranquilla, 2009, No 15 , pp. 139-157. 
La estructura del artículo está organizada de la siguiente manera: el primer apartado, desarrolla la modernización en clave local tratando de analizar cómo el aumento de la complejidad estatal fue paralelo a las transformaciones sociales y a los conflictos suscitados por las mismas. En segunda instancia, se analizan los orígenes de la Escuela de Servicio Social de Santa Fe a partir de una importante e innovadora Ley Provincial de Asistencia Social que requería ser implementada por expertos ya que el intento de utilizar a maestros para tal fin había sido insuficiente. Aquí se hace hincapié en el papel central del Estado provincial y de los funcionarios de la gestión liderada por el médico rosarino Joaquín Argonz, quien gobernó la provincia entre 1941 y el golpe de Estado de 1943. Siguiendo los lineamientos políticos de su predecesor, el radical antipersonalista Manuel de Iriondo, Argonz avanzó en las áreas de trabajo y salud promoviendo leyes y creando entidades estatales específicas. En tercera instancia, se reconstruyen los primeros tiempos de la Escuela a partir de analizar aspectos institucionales y educativos para pasar, finalmente, a estudiar las representaciones y las prácticas de las protagonistas: las primeras egresadas de la Escuela. Algunas de las preguntas que se intentan responder en esta parte son: ¿cuáles fueron las representaciones predominantes sobre las asistentes sociales? ¿De qué manera influyó la existencia de mujeres que buscaban integrarse plenamente en el mercado de trabajo? ¿Cuál era el perfil de las primeras egresadas de la Escuela que ingresaron en la estructura del estado provincial? En definitiva, se trata de un trabajo que retoma líneas transitadas por otros estudios y propone nuevos recorridos posibles para pensar los orígenes de esta institución educativa. ${ }^{5}$

\section{La modernización en clave local}

Durante el largo proceso de construcción de un Estado nación moderno existió una coexistencia y/o superposición de acciones estatales y privadas en diferentes planos de lo social. ${ }^{6}$ Las primeras áreas que se convirtieron en objeto de la intervención estatal fueron la higiene, la salud y la educación. ${ }^{7} \mathrm{La}$ denominada temprana cuestión social estuvo ligada a la aparición de un peligro (real y/o imaginario) de ruptura o desestabilización que sólo podía ser contrarrestada con la acción estatal. Un ejemplo fue la crisis epidémica de 1871 provocada por la fiebre amarilla cuyos efectos devastadores impulsaron un conjunto de disposiciones de distinto orden. En efecto, por un lado se ejecutó la segregación espacial

5. Los estudios sobre la Escuela de Servicio Social de Santa Fe que disponemos en la actualidad son: AAVV, Una aproximación a la recuperación de la historia de la Escuela de Servicio Social de Santa Fe, Tesina, Escuela de Servicio Social de Santa Fe, 1987; GENOLET, Alicia, La problemática de la asistencia social en un contexto de cambios (de la crisis de 1930 al fin de la guerra). La experiencia de la Escuela de Asistentes Sociales de Santa Fe y sus primeras egresadas, Tesis de Maestría, Universidad Nacional de Entre Ríos, 2004. PAPILI, Gustavo, El movimiento de reconceptualización en la Escuela de Servicio Social de la ciudad de Santa Fe durante las décadas de 19601970, Tesis de Maestría, Universidad Nacional de Entre Ríos, 2009.

6. En este contexto puede pensarse lo social como "el campo de la existencia humana situada entre el individuo y el Estado", en GONZALEZ LEANDRI, Ricardo, GÓNZALEZ BERNALDO, Pilar y SURIANO Juan, La temprana cuestión social..., Op. Cit., p. 17.

\section{Ibídem.}


de los enfermos y, por el otro, se crearon instituciones para controlar las epidemias y mantener a la población sana fuera del alcance del enemigo invisible. ${ }^{8}$ En este caso, como en otros, quedaron expuestos los límites de la acción "preventiva" que desarrollaban otras instituciones como la Iglesia, los filántropos y las entidades caritativas. De tal manera, el Estado impulsó la realización de estudios sobre las condiciones de vida de los sectores populares y ejecutó nuevas medidas sanitarias para mejorar el estado de salud de la población. Sin embargo, según ha argumentado Juan Suriano, todos estos cambios resultaron insuficientes para desencadenar políticas sociales más integrales desde el Estado. ${ }^{9}$

Hasta bien entrado el siglo $\mathrm{XX}$, las instituciones de beneficencia siguieron brindando atención médica y social allí donde el Estado no llegaba en forma directa. Un ejemplo destacable -por ser el modelo de otras entidades que proliferaron en todo el país- fue la Sociedad de Beneficencia de la Capital, creada en 1823 por iniciativa de Bernardino Rivadavia. Esta sociedad estaba conformada por mujeres pertenecientes a las clases altas que tenían una concepción asistencial basada en el "deber" del que brinda

8. Se crearon el Departamento Nacional de Higiene (1880), la entidad Asistencia Pública Municipal (1883), la Oficina Química Municipal y el Instituto Bacteriológico. Sobre el tema consultar ARMUS, Diego, "Consenso, conflicto y liderazgo en la lucha contra la tuberculosis. Buenos Aires 1870-1950, en SURIANO, Juan (compilador) La cuestión social en Argentina (18701943), La Colmena, Buenos Aires, 2000, y ARMUS, Diego, La ciudad impura. Salud, tuberculosis y cultura en Buenos Aires, 1870-1950, Edhasa, Buenos Aires, 2007.

9. SURIANO, Juan, "El Estado Argentino frente a los trabajadores urbanos: política social y represión, 18801916", en Anuario Escuela de Historia, Rosario, 19891990, $\mathrm{N}^{\circ} 14$, pp. $109-136$. la asistencia al pobre y no en el "derecho" que tiene éste a satisfacer sus necesidades. Dicha concepción caritativa era, fundamentalmente, la que transmitía la Iglesia católica, en la cual el acto piadoso tenía una doble función, a saber, engrandecía la propia esencia del donante $y$, al mismo tiempo, mitigaba el dolor ajeno. Tal como han señalado muchos autores, las tareas que desarrollaban las damas de la elite dentro de la Sociedad de Beneficencia estaban destinadas a atenuar las "consecuencias indeseables" de la pobreza y la miseria en los sectores populares urbanos. Así, muchos de los hospitales, albergues y otros espacios de contención para pobres estuvieron administrados por esta entidad que recibía fondos del Estado. ${ }^{10} \mathrm{Al}$ igual que en el ámbito nacional, la Sociedad de Beneficencia de Santa Fe, creada en 1860, administró y gestionó una serie de instituciones destinadas a la salud y la asistencia social que cumplieron un rol destacado en las primeras décadas del siglo XX. ${ }^{11}$ En efecto, esta institución

10. Los recursos que tenía la SNB provenían, fundamentalmente, de subsidios del Estado pero eran administrados en forma autónoma por las damas de dicha entidad. Según algunas estimaciones, en el año 1935 los recursos propios de la SNB apenas llegaban al $10 \%$ del total. En RAMACCIOTTI, Karina, La politica sanitaria del peronismo, Biblos, Buenos Aires, 2009, p. 26. $\mathrm{Al}$ respecto Luisina Perelmiter señala que el vínculo de la SNB con el Estado da cuenta de "una relación persistente entre lo público y lo privado a lo largo de la historia de la asistencia argentina”. PERELMITER, Luisina, La burocracia asistencial en funcionamiento. Relaciones y prácticas en la vida intima del Ministerio de Desarrollo Social de la Nación Argentina (2003-2009), Tesis Doctoral, Universidad de Buenos Aires, 2011, pp. 46-47.

11. La SB de Santa Fe fue fundada en 1860 por el gobernador Pascual Rosas con el objetivo de atender y dirigir las escuelas de niñas y los hospitales públicos que se enfrentaban a la escasez de personal capacitado. Esta institución recibía subvenciones del Estado nacional, provincial y municipal; también recibía donaciones de particulares, de firmas comerciales y de escuelas (estas 
tenía a su cargo el Hospital de Caridad en el cual funcionaba el Lazareto (espacio de aislamiento destinado a los enfermos de Lázaro o lepra); una escuela y el Asilo Buen Pastor. ${ }^{12}$ Con el tiempo, la estructura del Hospital de Caridad se fue complejizando con la incorporación de salas de distintas especialidades -como cirugía, radiología, otorrinolaringología- y nuevos servicios entre los que se encontraban los consultorios externos, los exámenes y las curaciones. Este hospital colaboró con la formación de enfermeras y, luego, de asistentes sociales dictando cursos en sus instalaciones.

La modernización santafecina fue generando nuevos problemas que sólo el Estado podía abordar mediante la creación de organismos especializados, con lo cual el aumento de la complejidad estatal fue paralelo a las transformaciones sociales, urbanísticas, económicas, culturales y políticas que afectaron de forma desigual las distintas regiones del país. Una de las transformaciones más relevante fue, sin lugar a dudas, la masiva llegada de inmigrantes. ${ }^{13}$ Muchos de ellos

últimas eran de menor envergadura). Si bien era la entidad local más destacada existían otras instituciones dedicadas a la beneficencia y atención de niños, pobres y enfermos como la Sociedad Conferencias de Señoras San Vicente de Paúl (creada en 1892) que tenía a su cargo un asilo para mendigos; la Sociedad Protectora de la Niñez (1902); el Hogar Atanasia Hernando de Durán (1935) para atender a los niños abandonados; Asociación El Centavo; Patronato de Leprosos (1940). GENOLET, Alicia, La problemática..., Op. Cit., pp. 59-60.

12. PIAZZESI, Susana y BOLCATO, Viviana, Hospital Iturraspe 100 años, UNL, Santa Fe, 2011, p. 19.

13. Entre 1881 y 1914 llegaron al país más de 4.200.000 inmigrantes, de los cuales casi la mitad eran de nacionalidad italiana. La mayoría llegaban atraídos por las excepcionales condiciones económicas y por las "cadenas migratorias" que proporcionaban vivienda, trabajo y sociabilidad al recién llegado. DEVOTO,

118 fueron los protagonistas del desarrollo fabril alrededor de la industria alimenticia, en particular, la provincia se especializó en la producción lechera a partir de la conformación de cooperativas. Por su parte, las condiciones geográficas favorecieron el crecimiento de las actividades relacionadas con el agro, las cuales promovieron un aumento demográfico basado en la proliferación -sobre todo en la zona sur y centro- de pequeños y medianos centros urbanos, cuya particularidad fue una estrecha vinculación con las áreas rurales. Según han advertido algunos estudios "la fluida comunicación entre campo, pequeños núcleos urbanos y ciudades portuarias fue un factor estructural en la complejidad de la trama social y asociativa -corporativa, sindical y política- santafesina". ${ }^{14}$ Esto implicó la circulación de ideas, de representaciones, de costumbres y, también, de conflictos que se extendieron a todas las zonas de la región.

E1 crecimiento de la industria estuvo orientado al mercado interno a partir del impacto provocado por la crisis económica mundial de 1930, la cual derrumbó los precios de los productos exportables (trigo, maíz y lino). Además de la industria lechera, se desarrollaron otros rubros como la producción arrocera, el cultivo del girasol y la producción algodonera. Tal como señala Oscar Videla por estos años "se inició una reformulación regional del espacio económico social de la provincia” que consistió fundamentalmente en la multiplicación de establecimientos y la incorporación de

Fernando, Historia de la inmigración, Sudamericana, Buenos Aires, 2004.

14. ASCOLANI, Adrián, “Santa Fe rural”, en Darío MACOR (director) Signos santafesinos en el Bicentenario, Ministerio de Innovación y Cultura de la Provincia de Santa Fe/CFI, Santa Fe, 2012, p. 274. 
mano de obra (especialmente durante la guerra)".${ }^{15}$ Con el devenir de los años, el sur de la provincia expandió sus instalaciones y su producción industrial (sobre todo cobra relevancia la industria metalúrgica) mientras que en el norte siguieron predominando las actividades agrícolas y ganaderas. ${ }^{16} \mathrm{La}$ intensificación de las jornadas para abastecer a un mercado de consumo en expansión junto a la tecnificación plantearon nuevas pautas a los obreros, quienes sufrían malas condiciones laborales, bajos salarios y el aumento de los accidentes de trabajo. Las transformaciones en el ámbito laboral estuvieron acompañadas de un crecimiento de la conflictividad y de las medidas de protesta de los trabajadores. El ingreso de grandes contingentes de mujeres al mercado laboral generó, desde fines del siglo XIX, debates en torno a distintos problemas relacionados con las condiciones de trabajo y su impacto sobre las funciones reproductivas, la desatención de las familias y la actividad sindical, entre otros. ${ }^{17}$

El proceso de urbanización en Santa $\mathrm{Fe}$ -como en otras ciudades del país- no estuvo exento de inconvenientes, sobre todo debido a la aceleración de los cambios. Tal como lo advirtió el intendente de Santa Fe, Agustín

15. VIDELA, Oscar, "Excepción y paradigma de la década infame 1930-1943", en VIDELA, Oscar (compilador) El siglo XX. Problemas sociales, politicas de Estado y economias regionales (1912-1976), La CapitalProhistoria, Rosario, 2006, p. 86.

16. SIMONASSI, Silvia, "Perfil industrial y dinámica social en la provincia de Santa Fe, 1943-1976", en AGUILA, Gabriela (coordinadora) De los cordones industriales a la integración del eje Mercosur (1940-2005), La Capital-Prohistoria, Rosario, 2006.

17. LOBATO, Mirta, "Entre La protección y la exclusión: discurso maternal y protección de la mujer obrera, Argentina 1890-1934", en SURIANO, Juan (compilador) La cuestión social en Argentina..., Op. Cit.
Zapata Gollán (1932-1934), el desarrollo había sido "caótico" y no existía de antemano un plan regulador integral para tratar los problemas de la misma. ${ }^{18} \mathrm{La}$ construcción de nuevas ciudades y la transformación de los viejos pueblos a partir de la extensión del sistema ferroviario, exigió la creación de marcos regulatorios tanto para la iniciativa privada como para la estatal. ${ }^{19} \mathrm{La}$ tendencia fue la expansión de espacios públicos para el aprovechamiento del tiempo libre y la preservación de la salud de la población junto a la extensión de los servicios de agua corriente y luz a los nuevos barrios periféricos de las ciudades. En este marco, la creación de la Comisión Provincial de la Vivienda Popular creada por Ley 2607 - sancionada en 1938 fue una respuesta contundente del gobierno conservador de Manuel de Iriondo (19371941) al problema de la vivienda popular. El objetivo de esta ley era construir casas y departamentos para obreros y empleados que comprobaran "sus antecedentes de moralidad y buenas costumbres" y que no poseyeran otros bienes raíces cuyas rentas superaran un mínimo estipulado. ${ }^{20}$ Los problemas en

18. COLLADO, Adriana María, "La defensa de los intereses ciudadanos en la Intendencia de Agustín Zapata Gollán. Santa Fe /1932-1934", en Revista América, Santa Fe, 1997, № 13.

19. LIERNUR, Francisco, "La construcción del país urbano", en LOBATO, Mirta (directora) El progreso, la modernización y sus limites (1880-1916), Nueva Historia Argentina T. V, Sudamericana, Buenos Aires, 2000.

20. Ley 2607. Texto original en ISILEG - Disponible en: <http://200.45.67.68/PRY_WWW_LEYES/PdfBuilder?nroLey $=2607 \&$ nro Version $=18$ tienePDF $=18$ nom breArchivo=Ley2607_9320.pdf> [Consulta: 18 de junio 2016] El gobierno de Argonz continuó con esta política social aunque no se alcanzaron a resolver los problemas habitacionales detectados tanto en el ámbito rural como en el urbano. Ver GENOLET, Alicia, La problemática..., Op. Cit., p. 58. 
los barrios periféricos motivaron la creación de sociedades vecinales con el objetivo de desarrollar tareas de mantenimiento (tales como el arreglo de calles, mejoramiento de parques y espacios verdes, colocación de columnas, etc.). Lo peculiar de este desarrollo es que además de estas tareas, las vecinales desarrollaban acciones de asistencia social respaldadas por el municipio. ${ }^{21}$

El recorrido por las calles de la ciudad era relativamente fluido gracias a la existencia del pavimento de asfalto en algunas de las vías principales de recorrido nortesur, mientras que en el centro santafesino predominaban las calles adoquinadas. La intensidad del tráfico en la capital provincial puede medirse en la evolución de la cantidad de los medios de locomoción: "la ciudad, que en 1921 no alcanzaba a tener registrados 300 vehículos automotores, había multiplicado notablemente este rubro para 1931, alcanzando los 4.000 vehículos (entre automóviles y camiones) en ese año". ${ }^{22}$ Los trabajadores podían desplazarse por los distintos barrios en los tranvías eléctricos y los ómnibus lo cual facilitaba la llegada al lugar de trabajo. Por estos años, tal como sucedió en Buenos Aires, proliferaron las asociaciones barriales, bibliotecas populares, vecinales y clubes deportivos que funcionaron como espacios de socialización, recreación y educación alternativa. ${ }^{23}$

21. En 1932 una ordenanza municipal les otorgó reconocimiento oficial especificando y delimitando sus funciones entre las que se encuentra-además del mejoramiento edilicio y barrial- la organización de servicios de Asistencia Social.

22. COLLADO, Adriana María, "La defensa de los intereses...", Op. Cit.

23. En la ciudad de Buenos Aires, a principios de la década del veinte, existían más de 40 bibliotecas, diez
En definitiva, la modernización santafesina durante las primeras décadas del siglo XX siguió las líneas generales que se presentaron en otros centros urbanos: urbanización, construcción de caminos, mejoras de las vías de comunicación, transformación de las formas de trabajo, etc. Por el otro lado, se generó un proceso de diferenciación provincial basado en la organización de la producción (el sur industrial y el norte orientado a la producción lechera y agropecuaria) a la vez que se integraban las zonas rurales y las urbanas a partir de un activo intercambio de prácticas culturales, ideas, trabajadores, conflictos. Dicha modernización -acelerada y caóticaacentuó conflictos y, al mismo tiempo, presentó nuevos problemas sociales que el Estado tuvo que enfrentar promoviendo la sanción de leyes; creando entidades y ministerios; diseñando programas sociales que podían colisionar con prácticas tradicionales de beneficencia y ayuda social llevadas adelante por asociaciones, vecinales, gremios y parroquias. En el siguiente apartado, se analizará la creación de la Escuela de Servicio Social de Santa Fe en el marco de la sanción de una Ley de Asistencia Social, una de las intervenciones que el Estado provincial llevó a cabo con el objeto de proteger a la infancia y a los sectores populares en el contexto de la modernización.

\section{Las experiencias en torno a la creación de escuelas}

Sobre el final del gobierno de Marcelo T. de Alvear (1922-1928), surge la idea de

años después habían aumentado a 90 y en los diez años siguientes llegaron a 200. Ver: GUTIERREZ, Leandro y ROMERO, Luis Alberto, Sectores populares, cultura y politica. Buenos Aires en la entreguerra, Sudamericana, Buenos Aires, 1995. 
crear una Escuela Nacional de Servicio Social para lo cual se ponen en marcha dos tareas: la primera era el estudio de entidades educativas y administrativas del servicio social europeo (que llevaron a cabo funcionarios del Ministerio de Justicia e Instrucción Pública en 1927), y la segunda era la elaboración del proyecto de creación de dicha escuela. ${ }^{24} \mathrm{E}$ objetivo de la institución educativa era "proporcionar enseñanza técnica y administrativa a los jóvenes que aspiren a ocupar puestos de asistencia y previsión sociales" ${ }^{25}$ y completar la educación de enfermeras, visitadoras de higiene $u$ otros trabajadores relacionados a la salud. ${ }^{26}$ Lo relevante de este fallido intento está en la fundamentación del proyecto, en el cual se explicaba que el interés del Estado por crear esta institución radicaba en utilizar, racional y eficazmente, los cuantiosos recursos que se invertían en asistencia sanitaria y social. Poco tiempo después, durante la explosiva coyuntura de 1930, se inauguró la primera

24. ALAYÓN, Norberto, "La primera escuela de Servicio Social (que no fue)". Disponible en <http://www.ts.ucr. ac.cr/binarios/pela/pl-000446.pdf> [Consulta: 18 de julio 2016]

25. Es conveniente señalar que el programa de estudios incluía materias de formación teórica como sociología, psicología, derecho, educación junto a otras materias de formación práctica como primeros auxilios, deportes, juegos, economía doméstica, entre otras.

26. En 1924 se creó el curso de Visitadora de Higiene de la Facultad de Ciencias Médicas de la UBA que apuntaba al perfeccionamiento técnico sanitario. Desde la perspectiva de Estela Grassi este avance en la profesionalización del área sanitaria no implicó, necesariamente, el abandono de algunos esquemas y preconceptos construidos anteriormente, ya que tanto las visitadoras como las damas de la elite apuntaron a fortalecer "la unidad moral de la familia" pudiendo establecer "una alianza táctica en función de las nuevas exigencias". GRASSI, Estela, Las mujeres y la profesión de asistente social... Op. Cit., p. 100.
Escuela de Servicio Social la cual dependía del Museo Social Argentino. La impronta de los médicos higienistas, en esta Escuela y en el curso de Visitadora de Higiene, fue decisiva tal como lo demuestran los planes de estudio claramente orientados a la prevención y profilaxis en el campo de la salud. ${ }^{27}$

En el transcurso de los años treinta el Estado avanzó en el objetivo de reformar/modernizar su estructura para intervenir más eficazmente en lo social..$^{28}$ De esta manera, durante los gobiernos conservadores de la segunda mitad de la década se creó el Registro Nacional de Asistencia Social (1937) para centralizar información de todas las obras de asistencia del territorio nacional; y la Dirección Nacional de Salud Pública y Asistencia Social (1943) dependiente del Ministerio del Interior cuyo objetivo era centralizar otras dependencias tales como el Departamento Nacional de Higiene y la Sociedad de Beneficencia. ${ }^{29}$ Paralelamente, en las

27. Entre los médicos higienistas que tuvieron una influencia determinante en la formación de estas instituciones educativas hay que mencionar a Alberto Zwank (Instituto de Higiene de la Facultad de Ciencias Médicas de la UBA); Julio Iribarne (Decano de la Facultad de Ciencias Médicas de la UBA); y Manuel Carbonell (Profesor de la Cátedra de Higiene de dicha Facultad). Ver IRIGOYEN FREYRE, Abelardo, $L a$ función del asistente social y la escuela de nurses, Ministerio de Salud Pública y Trabajo, Santa Fe, 1943, p. 19.

28. Sobre la coyuntura política de los años treinta y el rol de los conservadores ver MACOR, Darío, "Partidos, coaliciones y sistema de poder" en CATTARUZZA, Alejandro (director) Crisis económica, avance del Estado e incertidumbre política, Sudamericana, Buenos Aires, 2001, y en lo referido a la provincia de Santa Fe ver el texto de PIAZZESI Susana, Conservadores en provincia. El iriondismo santafesino 1937-1943, Universidad Nacional del Litoral, Santa Fe, 2009.

29. La Dirección Nacional de Salud Pública y Asistencia Social fue creada por el decreto 12.311 "apuntaba 
gobernaciones de Manuel María de Iriondo (1937-1941) y Joaquín Argonz (1941-1943), se implementaron una serie de políticas sociales tendientes a lograr la centralización y racionalización de la acción social. En este sentido, es importante recalcar la creación del Departamento de Salud Pública (1939) "que se delinea como un organismo técnicoadministrativo de control y de coordinación de acciones en el ámbito de la higiene pública, las condiciones del ambiente laboral y la asistencia médico social". ${ }^{30}$ Unos años después, en 1941, se crea el Ministerio de Salud y Trabajo dentro del cual se inserta el Departamento Provincial del Trabajo y otras dependencias dedicadas a la maternidad, al salario, etc. En síntesis, los gobiernos conservadores fueron actuando sobre los problemas presentados por la modernización a partir de la creación de nuevas áreas institucionales y la promulgación de leyes y normativas. Algunas de éstas son destacables, no sólo por su fin último -la lucha contra la mortalidad infantil- sino también por la visión centralizadora, integral y racionalista que sostenían respecto de la acción social.

Una norma que avanzó en este sentido fue la Ley 2608 de Asistencia Social y Hospitalaria sancionada en 1938; la cual establecía un plan general de construcción, instalación, sostenimiento y subvención

a la coordinación entre los servicios sanitarios y los asistenciales e intentaba romper con el subsidio estatal a las instituciones particulares". RAMACCIOTTI, Karina, La politica sanitaria del peronismo..., Op. Cit., p. 36.

30. MACOR, Darío y BACOLLA Natacha, "Centralismo y modernización técnica en la reformulación del Estado argentino. El caso provincial santafesino, 1930-1950", en Estudios interdisciplinarios de América Latina y el Caribe, Tel Aviv, 2009, V.XX, No 2, p. 2.

122 de establecimientos sanitarios (hospitales, colonias de niños débiles y convalecientes, colonias de alienados, institutos de diagnóstico y tratamiento del cáncer) en toda la provincia. Según la ley, el funcionamiento de las instituciones sanitarias podría estar en manos de las municipalidades o comunas, o de las sociedades de beneficencia. La Comisión de Hospitales y Asistencia Social -creada para implementar los distintos aspectos que establecía la legislación y realizar tareas de investigación ${ }^{31}$ - estaba dirigida por un presidente y dos vocales, los cuales debían ser médicos con cinco años de ejercicio profesional y con "antecedentes probados en materia de organización hospitalaria y asistencia social." ${ }^{2}$ También se estipulaba la incorporación de "personal técnico": un contador, un médico inspector y un ingenieroarquitecto para asesorar al Poder Ejecutivo respecto "la mejor forma de llevar a la práctica el plan general de creaciones y subvenciones hospitalarias y de información, organización y regulación de la asistencia social”. ${ }^{33}$

Una segunda disposición primordial para nuestro estudio es la Ley de Asistencia Social 3069 de 1942 la cual puede ser considerada el punto de partida del proceso de profesionalización en Santa Fe. Curiosamente la imposibilidad de aplicar esta ley impulsó la

31. La Comisión de Hospitales y Asistencia Social debía realizar un censo de todos los hospitales, salas de primeros auxilios, dispensarios, asilos, sociedades de beneficencia, sanatorios y clínicas particulares con el objetivo de elaborar un anteproyecto de Ley Orgánica y de Coordinación y Regulación de la Asistencia Social.

32. Ley 2608 de Asistencia Hospitalaria y organización de la asistencia social, Comisión de Hospitales y Asistencia Social de la Provincia de Santa Fe, Santa Fe, 1938, p. 5.

33. Ídem, p. 6. 
creación de una escuela de asistentes sociales en la ciudad. ¿Qué disponía esta ley? ¿Por qué no se la pudo implementar? ¿Cuáles fueron los problemas que se presentaron? El principal objetivo fue atender las necesidades primarias de los niños para combatir la mortalidad infantil y atenuar los efectos de la miseria en los sectores populares, para lo cual se preveía establecer comedores infantiles y proveer de vestidos a los niños de familias carentes de recursos. No obstante se consideraron otras variables educativas, recreativas y culturales tan necesarias como la nutrición. En tal sentido, la ley estipulaba la organización del turismo escolar y la construcción de dos casas-hogares en las ciudades de Santa Fe y Rosario para albergar a los niños "turistas"; la implantación de anexos en las fábricas y talleres para impartir el aprendizaje teóricopráctico de oficios y manualidades que beneficie a varones y mujeres desde los doce a los dieciocho años; y la creación de centros culturales y lugares para las "sanas diversiones" destinadas exclusivamente a los obreros: espectáculos teatrales, cinematográficos, conciertos musicales, torneos atléticos y de destreza. Además se preveía construir en distintas zonas de la provincia colonias de vacaciones para propiciar el turismo de los sectores trabajadores. Asimismo, la ley disponía que el Departamento de Sanidad y el Consejo General de Educación colaboraran con el Poder Ejecutivo para atender los problemas de asistencia social del niño. ${ }^{34}$ En síntesis, la Ley 3069 estipulaba la

34. El Departamento de Sanidad y el Consejo General de Educación debían asesorar al Poder Ejecutivo que, por su parte, designó "comisiones departamentales, seccionales o de distrito, las que actuarán en carácter ad-honorem para asesorar y ejercer el contralor y la vigilancia en la aplicación de esta Ley." Estas dos comisiones tuvieron su centro de acción en las ciudades de Rosario y Santa provisión de insumos culturales y materiales: vivienda, educación, vestimenta, alimentos, turismo, espectáculos artísticos y deportivos a todos los infantes de la provincia y también a los adultos pertenecientes a los sectores trabajadores.

Leoncio Gianello, quien se desempeñaba como Presidente del Consejo General de Educación $^{35}$, decía que esta ley junto a otras políticas del gobierno de la provincia -como la creación del Ministerio de Salud Pública y Trabajo; la creación del Patronato de Menores; la Caja de Previsión Social; la Ley de Tribunales de Menores; etc.- colocaban al espacio provincial a la vanguardia en materia de "servicio social" con respecto a todo el país: "Esta ley, la más completa del país, que habrá de servir de modelo a leyes de análoga orientación, a sancionarse en otras provincias, encara plenamente el problema asistencial del niño." ${ }^{36}$ Efectivamente, según el estudio de Alicia Genolet el plan general de acción social que contenía era una "iniciativa sin precedentes en el país". ${ }^{37}$ Para implementar dicho plan se dispuso -a través del Decreto No 100 de octubre de 1942- la formación

Fe. Ley 3069, Texto original, Cámara de Senadores de la Provincia de Santa Fe, Santa Fe, 28 de agosto de 1942.

35. Leoncio Gianello ocupó distintos cargos políticos desde los años treinta, de los cuales podemos destacar los siguientes: durante los gobiernos de Manuel María de Iriondo y Joaquín Argonz fue diputado por el departamento La Capital, Presidente de la Cámara de Diputados, Presidente del Consejo General de Educación. En el gobierno de Carlos Sylvestre Begnis ocupó el cargo de Ministro de Educación; mientras que durante el gobierno de Onganía fue Ministro de Gobierno, Justicia y Culto de Santa Fe.

36. Boletín de Educación, Provincia de Santa Fe, 5a Época, Santa Fe, 1943, No 36, p. 51.

37. GENOLET, Alicia, La problemática ..., Op. Cit., p. 95. 
de dos Juntas regionales una radicada en la ciudad de Santa $\mathrm{Fe}^{38}$ y otra en la ciudad de Rosario, denominadas Juntas Provinciales de Acción Social de la Primera y Segunda Circunscripción respectivamente.

La implementación de la ley requirió de escuelas para que funcionaran como centros asistenciales y de los maestros para desarrollar tareas de asistencia social, percibiendo una asignación extra sobre su sueldo. ${ }^{39}$ Los problemas y las limitaciones que reveló la adaptación de la estructura y los agentes educativos para implementar el programa social llevó al gobernador Iriondo a considerar necesaria la creación de una escuela de asistentes sociales en Santa Fe, siguiendo la experiencia rosarina. ${ }^{40}$ Desde la perspectiva del gobierno, dichos profesionales constituirían "el nexo de unión entre los recursos existentes en la zona y los centros auxiliares constituidos en las escuelas, instruirán a las maestras y organizaran cada lugar para que llegue la ayuda efectiva a cada hogar necesitado." ${ }^{41}$ De esta manera, siguiendo el argumento de Genolet, al "estructurarse el quehacer profesional como servicio en el contexto de una estructura de políticas y objetivos institucionales, se le asignó un lugar de intermediación entre las políticas del Estado y los pobres. Era una puesta en acto de un saber especializado que

38. La Junta que tenía su sede en la ciudad capital estaba conformada, entre otros, por el Dr. Emilio Sánchez Rizza y el Ingeniero Carlos A. Nickilson.

39. Decreto de S. P. No 100. Santa Fe, 8 de octubre de 1942. Mimeo.

40. Ver: BRITOS, Gabriel, La Asistencia Social en Rosario..., Op. Cit.

41. DE IRIONDO, Manuel, Discurso 1942, en GENOLET, Alicia, La problemática..., Op. Cit., p. 96. intervenía en la implementación de políticas y, simultáneamente, conservaba una imagen de benevolencia y altruismo mezclado con un conocimiento científico de los problemas sociales." ${ }^{42}$

Emilio Sánchez Rizza, miembro de una de las dos comisiones que asesoraba al Poder Ejecutivo, propuso que era conveniente estudiar el modelo de la primera escuela del país -la Escuela de Servicio Social del Museo Social Argentino- para diseñar la nueva institución. ${ }^{43} \mathrm{E} 1$ proyecto fue presentado $\mathrm{y}$ aprobado por el Consejo de Educación el cual explicó que la Escuela nacía de "la necesidad de capacitar vocaciones" para contribuir a los proyectos de intervención social que el gobierno provincial había puesto en marcha. ${ }^{44}$ Así es posible afirmar que el surgimiento de la Escuela estuvo claramente ligado a las necesidades del mundo de la política. Para el ministro de Salud Pública y Trabajo de la provincia de Santa Fe, Dr. Abelardo Irigoyen Freyre, la asistencia social, la cultura y la política estaban inevitablemente vinculadas. Según su concepción eran parte de la "política cultural de un gobierno."

No es difícil imaginar cómo la Asistencia Social, aplicada conscientemente, y con el criterio más amplio puede influir sobre la vida de la colectividad, sobre la misma constitución política-administrativa de un país, excitando el interés de los gobiernos por mantener bien alta la vitalidad de sus

42. GENOLET, Alicia, La problemática..., Op. Cit., p. 103.

43. SÁNCHEZ RIZZA, Emilio, Apuntes para la Historia de la Escuela de Servicio Social de Santa Fe, Santa Fe, s/f.

44. Boletín de Educación, Provincia de Santa Fe, 5a Época, Santa Fe, 1943, No 36, p. 50. 
habitantes y realizar el máximo esfuerzo financiero para lograr este objetivo. ${ }^{45}$

Irigoyen Freyre apoyó decididamente el proyecto de creación de la Escuela destacando la necesidad de contar con conocimiento técnico para solucionar los problemas sociales porque "el sentido común y el buen corazón pocas veces solucionan definitivamente problemas de orden social". ${ }^{46}$ Uno de los objetivos del Estado provincial era la "coordinación" de la asistencia social a través de las políticas públicas, esto es, aunar todos los esfuerzos con "criterio científico en beneficio del género humano". ${ }^{47}$ Paralelamente, el ministro pensaba que había que garantizar el acceso igualitario y gratuito a la atención médica. Desde su perspectiva el Estado era el único responsable de la salud de la población, por tanto abogaba "por la conformación de un sistema de servicios único”. ${ }^{48}$ En esta visión integral de la salud pública la realización de acciones preventivas podían ser llevadas a cabo por las asistentes sociales.

Tal como se ha visto hasta aquí, la Escuela surge a partir de los problemas que se presentaron durante la aplicación de una normativa provincial sancionada para intervenir en lo social. Fue en este marco que se hizo eviden-

45. IRIGOYEN FREYRE, Abelardo, La función del asistente social y la escuela de nurses, Ministerio de Salud Pública y Trabajo, Santa Fe, 1943, p. 14.

46. Citado en BRITOS, Gabriel, Asistencia Social en Rosario..., Op. Cit., p. 74.

47. IRIGOYEN FREYRE, Abelardo, La función del asistente social..., Op. Cit., p. 15.

48. BELMARTINO, Susana, "Coyuntura crítica y cambio institucional en salud: Argentina en los años '40”, en Salud Colectiva, Buenos Aires, 2007, V. III, No 2, p. 178. te la carencia de agentes estatales entrenados para tal fin. En el apartado siguiente veremos que la construcción de una cultura profesional del asistente social se encontró vinculada a la cultura política de un Estado que fue progresivamente definiéndose como interventor y regulador de los conflictos sociales.

\section{La vida en la Escuela de Servicio Social de Santa Fe}

Las actividades en la Escuela comenzaron en el mes de mayo de 1943 con un número considerable -aproximadamente $80-$ de estudiantes en el edificio donde había funcionado la escuela fiscal No 3, en la calle Rivadavia 2933 de la capital provincial. Este edificio carecía de las condiciones edilicias mínimas -lo cual generó el traslado a otro establecimiento- y el equipamiento era prácticamente inexistente. ${ }^{49} \mathrm{La}$ Escuela, que durante los primeros meses estuvo bajo la órbita del Consejo de Educación, fue transferida a la Junta Provincial de Acción Social (1 $1^{\text {a }}$ Circunscripción). A principios de 1944 el establecimiento pasó a denominarse Escuela de Servicio Social de Santa Fe y obtuvo el reconocimiento nacional de los títulos expedidos por la misma. ${ }^{50}$

49. Al poco tiempo de comenzar las clases se decidió el traslado de la Escuela (que pasó de la calle Rivadavia 2933 a San Martín 2337 donde funcionaba la sede de la Junta Central de Acción Social). Por el otro lado, se adquirieron los muebles indispensables -como los bancos- para el dictado de las clases. La creación de la Biblioteca de la Escuela fue un trabajo conjunto entre los distintos actores que formaban parte de la institución: Emilio Sánchez Rizza donó nueve meses de su sueldo y el Centro de Estudiantes -bajo la presidencia de María Teresa Pérez Argüello- recolectó dinero entre las alumnas para adquirir libros. Acta No 14 del Centro de Estudiantes de la Escuela de Asistentes Sociales de Santa Fe, Santa fe, 10/07/1943.

50. El 21 de diciembre de 1944 el presidente de facto 
Los docentes de la Escuela eran sugeridos por el Consejo Directivo -conformado por docentes y directivos de la institución educativa- a la Junta Central de Acción Social que a su vez los proponía al Poder Ejecutivo para ser finalmente designados por éste. Asimismo, el reglamento interno aprobado en 1944 disponía la preferencia por los/las estudiantes y futuros/as egresados/ as de la Escuela para ocupar los cargos que se crearan. ${ }^{51} \mathrm{La}$ primera planta docente estaba integrada por el Dr. Roberto Lavagna (Economía Doméstica), Dr. Luis Bonsembiante (Psicología), Dr. Francisco Menchaca (Higiene y Puericultura), Dr. Francisco Magín Ferrer (Derecho Usual), y Dr. Emilio Sánchez Rizza (Economía Política). En 1944 fueron incorporados el Dr. Mariano Tissembaum (Economía y Legislación Social), Dr. Héctor Coll (Higiene y Medicina Social), Dr. Gerardo Laprido (Infancia abandonada y delincuente), Dra. Emma Guastavino Ureta (Servicio Social).52 Muchos de estos reconocidos profesionales, médicos y abogados, ocuparon cargos de relevancia en el Estado. En efecto, Guastavino Ureta fue Directora General de Bienestar Social del Ministerio de Salud Pública y Bienestar Social de la Provincia de Santa Fe. Emilio Sánchez Rizza fue Director General de Estadística de la provincia donde

Edelmiro Farrel, a través del Decreto No 33733-1944, estableció la validez nacional para los títulos otorgados por la Escuela. De todos modos, el trámite llevó su tiempo ya que en 1948 se activa la gestión para obtener la nacionalización de los títulos dispuesta por dicho decreto. Ver: AAVV, Una aproximación a la recuperación..., Op. Cit, p. 163.

51. “Transformación de la escuela de asistentes sociales", EL ORDEN, Santa Fe, 5/04/1944, p. 1.

52. SÁNCHEZ RIZZA, Emilio, Apuntes para la Historia..., Op. Cit.:

126 impuso cambios trascendentales en dicha agencia. ${ }^{53}$ Por su parte, Teresa Vigetti -una de las primeras asistentes sociales recibidas en la Escuela y directora de la misma entre 1958 y 1971- se destacó dentro de la estructura estatal como Jefa de Estadística de la Provincia.

La construcción de un nuevo campo de saber y la inserción de los profesionales en el Estado fue un proceso que presentó una serie de problemas, difícilmente calculados de antemano por los funcionarios y políticos que promovieron la creación de la Escuela. En las primeras prácticas y acciones profesionales llevadas a cabo por las flamantes alumnas fue notable el rechazo de los empleados de la administración estatal y la resistencia a la introducción de nuevas prácticas.

Tropezamos con la incomprensión general, el desconocimiento de nuestra función específica, el espíritu cerrado y la burocracia de algunas Oficinas que rechazan toda innovación, etc. Es necesario que pase un cierto período de tiempo, el más difícil, hasta que se produzca la mutua adaptación entre las instituciones existentes y las nuevas funciones del Asistente Social. ${ }^{54}$

Desde el Centro de Estudiantes se trabajó por la construcción de una cultura profesional que definiera y legitimara el rol de las/ los asistentes sociales. Así se organizaron conferencias enfatizando "la importancia del

53. "En menos de seis años ha transformado la Dirección General de Estadística de la provincia en un organismo esencialmente técnico, cuyos procedimientos han sido recomendados en tres Congresos nacionales y cuyos trabajos gozan de prestigio en el orden nacional y mundial."'Distinción a un profesional de nuestro medio", El Litoral, Santa Fe, 05/04/1941, p. 3.

54. Nuestra Voz, Boletín del Centro de Estudiantes de la Escuela de Servicio Social, Santa Fe, 1945, Año 1, No 1, p. 2. 
Asistente Social, y el rol importantísimo que desempeña en toda sociedad" ${ }^{55}$; se realizó la Jornada Provincial de Servicio Social para "dar a conocer el verdadero panorama de lo que constituye la práctica del Servicio Social"56; entre otras actividades semejantes. Se trató de un largo proceso ya que todavía en los años cincuenta se constituyó una comisión integrada por representantes del Centro de Estudiantes y miembros del Centro de Asistentes Sociales "con el objetivo de difundir la existencia de la carrera y la comprensión de la labor profesional. ${ }^{" 57} \mathrm{La}$ profesionalización, lejos de excluir la práctica investigativa, la promovía a partir de la creación de un centro de investigaciones para estudiar los problemas regionales. ${ }^{58} \mathrm{La}$ organización de este espacio fue un trabajo arduo que llevó varios meses y finalmente se concretó el 3 de agosto de 1945, ya que se pensaba que el/la asistente social no debía limitarse a aplicar sus conocimientos técnicos sino que simultáneamente tenía que "contribuir a formar la conciencia social del medio en que

55. Acta No 40 del Centro de Estudiantes de la Escuela de Asistentes Sociales de Santa Fe, 12 de junio de 1946. La primera conferencia estuvo a cargo de Sánchez Rizza cuyo título fue "Misión del Asistente Social" y fue abierta a la comunidad que pudo escucharla en la Biblioteca Moreno.

56. Revista de la Escuela de Servicio Social de Santa Fe, Año 1, noviembre-diciembre de 1946 , No 5, p. 70. Los temas a tratar en dicha Jornada eran 1) la práctica de servicio social en las áreas rural, industrial, escolar, sanitaria, infantil y 2) el servicio social planteado en el Plan Trienal del Gobierno de la Provincia. Ver también: "Bases para la jornada provincial de servicio social", EL ORDEN, Santa $\mathrm{Fe}, 26 / 02 / 1947$, p. 1.

57. AAVV, Una aproximación a la recuperación..., Op. Cit, pp. 167.

58. MENCHACA, Francisco, “¿Qué función cumple una escuela de asistente sociales?", El Litoral, Santa Fe, 15/03/1944, p. 4. actúa, sin incurrir en dogmatismos". ${ }^{59}$ Para lograr la formación de estos profesionales era imprescindible transformar "nuestras escuelas de servicio social en auténticos fermentarios, en verdaderos talleres universitarios." ${ }^{00}$

En síntesis, la construcción de una cultura profesional fue un proceso de larga duración que convocó a distintos sectores, a saber, a los funcionarios, a los docentes, a los directivos y a los/las estudiantes de la flamante Escuela. El proceso no estuvo exento de los conflictos personales e institucionales que pueden presentarse al integrar nuevos expertos en la estructura del Estado provincial. La particularidad del caso de la Escuela de Servicio Social de Santa Fe es que incluyó dentro de su identidad profesional la práctica investigativa desde sus primeros años.

\section{"Una joven modelo": la profesión en clave femenina}

La población femenina en la Escuela de Servicio Social de Santa Fe fue mayoritaria desde los comienzos de la institución. Según los registros en 1945 egresaron de la Escuela 44 trabajadoras sociales, todas mujeres.$^{61}$ Esto fue así a pesar de que entre los requisitos de ingreso a la Escuela no había ninguna cláusula respecto al género; los requerimientos eran ser argentino/a, tener título de maestro/a normal o bachiller, ser menor de 35 años, poseer certificado de buena conducta y de "capacidad


debe ser vanguardia de ideales de renovación”, El Litoral, Santa Fe, 26/09/1945, p. 4.

60. Ibídem.

61. Planilla de egresadas 1945. Archivo de la carrera de Trabajo Social, UNL. 
física". Asimismo se estipulaba que los aspirantes a ingresar como estudiantes debían pasar un examen de aptitudes y capacidad vocacional. ¿Por qué entonces predominaban las estudiantes mujeres? ¿Cuáles aptitudes debía tener una/un estudiante de la Escuela de Asistentes sociales en Santa Fe?

Emma Guastavino Ureta argumentaba que lo esencial era cierta sensibilidad definida por la "simpatía por las necesidades humanas de los que nos rodean" y la "valoración de la justicia social”. Según ella, las otras cualidades se podían alcanzar "a través de una experiencia disciplinada y una preparación eminentemente práctica y realista dada en las Escuelas de Servicio Social a base de horas de estudio, elaboración del propio juicio crítico profesional, de autodisciplina a los que se agregan los rigores de una práctica profesional supervisada." ${ }^{62}$ No obstante, el ministro Irigoyen Freyre, al inaugurar la Escuela, asimilaba la profesión al género femenino afirmando que,

La asistente social debe ser una joven modelo de salud, de limpieza y de orden. Su conducta ejemplar, su actitud cariñosa y enérgica al mismo tiempo; su inteligencia despejada, su bagaje intelectual grande y disciplinado. La base de su acción tendrá como principal factor la más absoluta sinceridad para el prójimo y para consigo misma, porque es ella la que deberá ser la gran propagandista de los ideales higiénicos y sociales. Y para ello, debe sentirlos profundamente manteniéndose en relaciones constantes con entidades, organizaciones sanitarias y de asistencia social, escuelas, ambientes pedagógicos,

62. GUASTAVINO URETA, Emma, "Previsión SocialSeguridad Social-Servicio Social”, El Litoral, Santa Fe, 18/07/1947, p. 4.

128 etc. Su vida debe estar consagrada al estudio y a la acción. ${ }^{63}$

Atravesados por el paradigma maternalista predominante, los funcionarios del Estado provincial asignaban a las mujeres cualidades domésticas y afectivas (limpieza, orden, cariño, comprensión, etc.). Para Irigoyen Freyre las tareas prioritarias de las asistentes sociales eran "vigilar, indagar, aconsejar, dirigir y educar" con lo cual era imprescindible ganarse el afecto y consideración de las familias obreras. Si observamos las características socioeconómicas de las primeras egresadas vemos que pertenecían a familias de clase media cuyos padres eran empleados del sector servicios (ferrocarriles, bancos), comerciantes y docentes. Estas mujeres provenientes de hogares "acomodados" manifestaron su sensibilidad frente a la pobreza; la necesidad de ampliar sus estudios (ya que muchas de ellas eran docentes) y, también, la imposibilidad de acceder a otros estudios fuera de la ciudad y lejos de sus familias. Teresa Vigetti, por ejemplo, comenzó la carrera de asistente social una vez finalizada la escuela secundaria con orientación de perito mercantil. A ella no la guiaba el interés por ampliar sus conocimientos profesionales y obtener otro título, sino más bien, según su propio testimonio, su ilusión era "cambiar" el estado de cosas. En sus años como alumna de la Escuela formó parte del grupo que impulsó la conformación del Centro de Estudiantes y participó de todas las actividades que desde allí se promovían. ${ }^{64} \mathrm{Su}$ recorrido biográfico

63. Boletín de Educación, Provincia de Santa Fe, 5a Época, Santa Fe, 1943, № 36, p. 57.

64. Algunas de las actividades organizadas por el Centro de Estudiantes fueron: visitas a hospitales, reparto de dulces en las escuelas (en ocasión de festejos patrios repartían golosinas y escarapelas), organización de 
nos muestra que, lejos de reproducir el paradigma tradicional, Vigetti fue una mujer independiente, moderna y dedicada a su carrera profesional. ${ }^{65}$

Con el correr de los años el número de egresadas fue disminuyendo notablemente, lo cual probablemente pudo haber sido consecuencia del cambio realizado en los planes de estudios que significó una demanda mayor de dedicación al aumentar las horas de clases y práctica profesional. ${ }^{66}$ La deserción fue un problema que preocupó a los directivos y estudiantes de la Escuela tal como lo demuestran las encuestas realizadas por el Centro para establecer los motivos de esta tendencia. ${ }^{67}$ Una de las hipótesis es que la interrupción del cursado y abandono de la carrera estuvieron relacionados a las rígidas condiciones que impuso el reglamento interno de 1944. E1 mismo establecía que los/las estudiantes que sacaran tres veces insuficiente en una materia no podrían continuar sus estudios; que la asistencia era obligatoria por lo que era imposible rendir materias como alumno libre; que no se otorgaban equivalencias por materias cursadas en otros institutos; que los estudiantes no podían inscribirse al año siguiente si adeudaban más de una materia

conferencias, edición de un boletín, entre otras.

65. RUBINZAL, Mariela, Historia de la Escuela de Servicio Social de Santa Fe (1943-2013), UNL, Santa Fe, 2014.

66. En 1946 se recibieron 16 asistentes sociales; en 1947 egresaron 18; en 1948 terminaron sus estudios 11 alumnas, mientras que en 1949 sólo 4 personas lograron terminar sus estudios. GENOLET, Alicia, $L a$ problemática..., Op. Cit., p. 113.

67. Acta No 32 y Acta No 59 del Centro de Estudiantes de la Escuela de Asistentes Sociales de Santa Fe, 10 de abril de 1946 y 1 de junio de 1948 respectivamente. del programa, entre otras disposiciones. ${ }^{68}$ En 1952 las autoridades decidieron flexibilizar someramente los requisitos para el ingreso a la carrera reemplazando el examen escrito y oral por una prueba vocacional, y para evitar la deserción estudiantil permitieron que los/ las estudiantes que adeudaban una o dos materias pudieran inscribirse al siguiente año. ${ }^{69}$

La mayoría de las primeras egresadas se insertaron en la Dirección de Acción Social -dependiente del Ministerio de Salud Pública y Trabajo- la cual tenía agencias en los barrios de la ciudad. También se incorporaron en lugares donde previamente habían realizado sus prácticas, como por ejemplo el Servicio Social Escolar, la Educación Especial con Ciegos, el Servicio Social Hospitalario, el Patronato de Menores, el Juzgado de Menores, el Departamento de Servicio Social en la Administración Nacional del Agua y el Servicio Social Rural.

También podían desempeñar tareas en otras áreas del Estado como la Dirección de Estadística de la Provincia que -como ya hemos mencionado- fue dirigida en distintos momentos por dos profesores de la escuela, Sánchez Rizza y Teresa Vigetti. En sus visitas a los barrios carenciados y a las escuelas, las asistentes sociales iban en general acompañadas por visitadores de higiene y auxiliares de servicio social, quienes se formaban en el mismo ámbito educativo. La función de los visitadores y visitadoras era difundir normas de higiene y economía doméstica, consideradas para

68.“"Transformación de la escuela de asistentes sociales”, El Orden, Santa Fe, 5/04/1944, p. 4.

69. AAVV, Una aproximación a la recuperación..., Op. Cit. 
algunos "minucias para las cuales el médico no tiene tiempo." ${ }^{70}$ Por su parte, los auxiliares acompañaban a los asistentes sociales y se encargaban de las tareas administrativas, registros y trámites. Las entrevistas y los diagnósticos quedaban en manos de los asistentes, quienes -desde la perspectiva del ministro Irigoyen Freyre- tenían funciones "más variadas" ya que no sólo actuaban sobre la enfermedad sino también sobre las causas de la misma; reeducando a los padres, orientando a la madre, difundiendo valores, atendiendo a los niños, buscando empleo para los adultos, etc. Pero, al mismo tiempo, los campos de trabajo eran comunes y ambas profesiones podían llevar adelante prácticas conjuntas como, por ejemplo, en lo referido a la "higiene sexual". ${ }^{71}$ Esto planteaba la necesidad de delimitar y diferenciar las formaciones profesionales tal como puede verse en los debates que se producían entre los integrantes del Centro de Estudiantes. ${ }^{72}$

Las primeras profesionales formadas en la Escuela de Servicio Social de Santa Fe se insertaron en dependencias estatales durante el gobierno peronista. Según los testimonios recogidos por Alicia Genolet las asistentes vivieron momentos de desencanto por los límites de una actividad que habían considerado mucho más efectiva de lo que

70. Sociedad de Higiene y Microbiología. Crónica de la sesión del 3/011/1925, citado en GRASSI, Estela, Las mujeres y la profesión de asistente social..., Op. Cit., p. 71.

71. Boletín de Educación, Provincia de Santa Fe, 5a Época, Santa Fe, 1943, No 36, p. 57.

72. Por ejemplo, el debate en torno al uso de una insignia común para todos los estudiantes de la Escuela, o por el contrario, la diferenciación entre los distintivos correspondientes a las asistentes sociales y a las auxiliares. La primera opción fue la que se impuso después de la consulta con los directivos de la Escuela. resultó ser; de temor porque tenían ideas políticas - distintas a la de los funcionariosque podrían hacerles perder su trabajo; entre otras sensaciones de abatimiento por no poder resolver problemas de la gente de los barrios periféricos. Algunas de ellas pensaban que la política de la Dirección de Acción Social se reducía al asistencialismo reforzado por las acciones de las mujeres de las Unidades Básicas que muchas veces se superponían a las de las profesionales del Trabajo Social.

\section{Consideraciones finales}

Uno de los objetivos de este trabajo fue analizar el rol del Estado provincial en la creación de la Escuela de Servicio Social de Santa Fe. En este marco pudimos ver cómo la formación profesional se convirtió en una política pública a raíz de las dificultades que se presentaron durante la implementación de una Ley Integral de Asistencia Social sancionada durante los gobiernos conservadores locales de los años treinta. De esta manera, confirmamos una de nuestras hipótesis la cual presuponía que la creación de la Escuela por parte del Estado provincial fue una estrategia, entre otras, para abordar los problemas sociales. El hecho de que las primeras asistentes sociales se hayan insertado en dependencias estatales antes que en entidades privadas confirma que el Estado santafecino había alcanzado una evolución institucional basada en la centralización, la eficiencia y la racionalización preparada para alojar a estos expertos. Lo cual no implica que el ingreso de los mismos no haya causado conflictos con otros agentes administrativos que se resistían a implementar nuevas pautas laborales. Por esto, entre otras 
cosas, afirmamos que en los orígenes de la profesionalización del trabajo social existió una matriz conflictiva que, en rasgos generales, se vincula al avance del Estado sobre áreas antes gestionadas por entidades no estatales. Por su parte, las primeras asistentes sociales introdujeron nuevas prácticas para llegar a los sectores populares y al mismo tiempo reprodujeron patrones sociales y culturales tradicionalistas dentro de las cuales fueron formadas profesionalmente. No obstante, la carrera abrió una serie de posibilidades culturales, económicas, familiares y políticas que, en algunos casos, imprimieron un giro a las trayectorias de vida de las primeras egresadas de la Escuela.

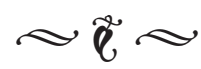

Recibido: 25-06-2016

Aceptado: 31-10-2016

Publicado: 30-12-2016 


\section{Bibliografía}

AAVV, Una aproximación a la recuperación de la historia de la Escuela de Servicio Social de Santa Fe, Tesis colectiva, Santa Fe, Escuela de Servicio Social de Santa Fe, 1987.

ALAYÓN, Norberto, Hacia la historia del trabajo social en la Argentina, Celats, Lima, 1980.

ALAYÓN, Norberto, “Acerca del trabajo social y la antimodernidad”, en Social Work E̋ Society, Essen, 2004, V.II, No 2, pp. 279-284.

ARMUS, Diego, “Consenso, conflicto y liderazgo en la lucha contra la tuberculosis. Buenos Aires 18701950, en SURIANO, Juan (compilador) La cuestión social en Argentina (1870-1943), La Colmena, Buenos Aires, 2000.

ARMUS, Diego, La ciudad impura. Salud, tuberculosis y cultura en Buenos Aires, 1870-1950, Edhasa, Buenos Aires, 2007.

ASCOLANI, Adrián, "Santa Fe rural”, en Darío MACOR (director) Signos santafesinos en el Bicentenario, Ministerio de Innovación y Cultura de la Provincia de Santa Fe/CFI, Santa Fe, 2012.

BECERRA SOLÁ, Malena y BECERRA Natalia, "Intervención social en la Argentina de los años 30: la profesionalización de la asistencia social”, en Historia del Caribe, Barranquilla, 2009, No 15, pp. 139-157.

BELMARTINO, Susana, “Coyuntura crítica y cambio institucional en salud: Argentina en los años “40”, en Salud colectiva, Buenos Aires, 2007, V. 3, No 2.

BRITOS, Gabriel, Asistencia Social en Rosario. Historia de su formación profesional, UNR, Rosario, 2003.

COLLADO, Adriana María, "La defensa de los intereses ciudadanos en la Intendencia de Agustín Zapata Gollán. Santa Fe /1932-1934”, en Revista América, Santa Fe, 1997, No 13.

DEVOTO, Fernando, Historia de la inmigración, Sudamericana, Buenos Aires, 2004.

GUY, Donna, Las mujeres y la construcción del Estado de Bienestar. Caridad y creación de derechos en Argentina, Prometeo, Buenos Aires, 2011.

GENOLET, Alicia, La problemática de la asistencia social en un contexto de cambios (de la crisis de 1930 al fin de la guerra). La experiencia de la Escuela de Asistentes Sociales de Santa Fe y sus primeras egresadas, Tesis de Maestría, Universidad Nacional de Entre Ríos, 2004.

GÓNZALEZ LEANDRI, Ricardo, "La nueva identidad de los sectores populares", en Alejandro CATTARUZZA (director) Crisis económica, avance del Estado e incertidumbre politica (1930-1943), Sudamericana, Buenos Aires, 2001.

GONZALEZ LEANDRI, Ricardo, GÓNZALEZ BERNALDO, Pilar y SURIANO Juan, La temprana cuestión social. La ciudad de Buenos Aires durante la segunda mitad del siglo XIX, Consejo Superior de Investigaciones Científicas (CISC), Madrid, 2010. 
GUTIERREZ Leandro y ROMERO, Luis Alberto, Sectores populares, cultura y politica. Buenos Aires en la entreguerra, Sudamericana, Buenos Aires, 1995.

GRASSI, Estela, Las mujeres y la profesión de asistente social. El control de la vida cotidiana, Humanitas, Buenos Aires, 1989.

LIERNUR, Francisco, "La construcción del país urbano" en LOBATO, Mirta (directora) El progreso, la modernización y sus limites (1880-1916), Nueva Historia Argentina T. V, Sudamericana, Buenos Aires, 2000.

LOBATO, Mirta, "Entre La protección y la exclusión: discurso maternal y protección de la mujer obrera, Argentina 1890-1934”, en SURIANO, Juan (compilador) La cuestión social en Argentina (1870-1943), La Colmena, Buenos Aires, 2000.

MACOR, Darío y BACOLLA Natacha, "Centralismo y modernización técnica en la reformulación del Estado argentino. El caso provincial santafesino, 1930-1950”, Estudios interdisciplinarios de América Latina y el Caribe, Tel Aviv, 2009, V. XX, No 2.

MACOR, Darío (director) Signos santafesinos en el Bicentenario, Ministerio de Innovación y Cultura de la Provincia de Santa Fe, Santa Fe, 2012.

MACOR, Darío, "Partidos, coaliciones y sistema de poder", en CATTARUZZA, Alejandro (director) Crisis económica, avance del Estado e incertidumbre política, Sudamericana, Buenos Aires, 2001.

PAPILI, Gustavo, El movimiento de reconceptualización en la Escuela de Servicio Social de la ciudad de Santa Fe durante las décadas de 1960-1970, Tesis de Maestría, Universidad Nacional de Entre Ríos, 2009.

PARRA, Gustavo, "Antimodernidad y Trabajo Social. Reflexiones en torno a la génesis de la profesión. Disponible en: <http:/www.ts.ucr.ac.cr/binarios/congresos/reg/slets/slets-016-136.pdf> [Consulta: 18 de julio 2016], s/f.

PERELMITER, Luisina, La burocracia asistencial en funcionamiento. Relaciones y prácticas en la vida intima del Ministerio de Desarrollo Social de la Nación Argentina (2003-2009), Tesis Doctoral, Universidad de Buenos Aires, 2011.

PIAZZESI, Susana y BOLCATO, Viviana, Hospital Iturraspe. 100 años, UNL, Santa Fe, 2011.

PIAZZESI Susana, Conservadores en provincia. El iriondismo santafesino 1937-1943, Universidad Nacional del Litoral, Santa Fe, 2009.

RAMACCIOTTI, Karina, La politica sanitaria del peronismo, Biblos, Buenos Aires, 2009.

ROZAS PAGAZA, Margarita, Intervención profesional en relación a la cuestión social, Editorial Espacio, Buenos Aires, 2001.

RUBINZAL, Mariela, Historia de la Escuela de Servicio Social de Santa Fe (1943-2013), UNL, Santa Fe, 2014. 
SIMONASSI, Silvia, "Perfil industrial y dinámica social en la provincia de Santa Fe, 1943-1976", en AGUILA, Gabriela (coordinadora) De los cordones industriales a la integración del eje Mercosur (19402005), La Capital-Prohistoria, Rosario, 2006.

SURIANO, Juan (compilador) La cuestión social en Argentina (1870-1943), La Colmena, Buenos Aires, 2000.

SURIANO, Juan, "El Estado Argentino frente a los trabajadores urbanos: política social y represión, 18801916" en Anuario Escuela de Historia, Rosario, 1989-1990, № 14, pp. 109-136.

TENTI FANFANI, Emilio, Estado y pobreza: estrategias tipicas de intervención (2 volúmenes), CEAL, Buenos Aires, 1989.

VIDELA, Oscar, "Excepción y paradigma de la década infame 1930-1943", en VIDELA, Oscar (compilador) El siglo XX. Problemas sociales, politicas de Estado y economías regionales (1912-1976), La Capital-Prohistoria, Rosario, 2006. 